Article

\title{
Optimal Design of an Axial-Flux Permanent-Magnet Motor for an Electric Vehicle Based on Driving Scenarios
}

\author{
Yee Pien Yang ${ }^{1,2, *}$ and Guan Yu Shih ${ }^{3}$ \\ 1 Department of Mechanical Engineering, National Taiwan University, 1, Section 4, Roosevelt Road, \\ Taipei 106, Taiwan \\ 2 Mechanical and Systems Research Labortories, Industrial Technology Research Institute, 195, Section 4, \\ Chung Hsing Road, Hsinchu 310, Taiwan \\ 3 CADMEN, Taiwan Auto-Design Corporation, 11 F, No. 68, Section 2, Xianmin Boulevard, \\ New Taipei City 220, Taiwan; kevin.shih@cadmen.com \\ * Correspondence: ypyang@ntu.edu.tw; Tel.: +886-233-662-682; Fax: +886-223-631-755
}

Academic Editor: K. T. Chau

Received: 16 February 2016; Accepted: 1 April 2016; Published: 13 April 2016

\begin{abstract}
This paper proposes a driving-scenario oriented optimal design of an axial-flux permanentmagnet (AFPM) motor for an electric vehicle. The target torque and speed (TN) curve is defined as three operation zones-constant torque, maximum direct current, and maximum voltage-based on the driving scenario. The AFPM motor is designed to minimize energy consumption based on the motor weight and the frequent operating points of a driving cycle. The final result shows that the electric vehicle driven by the proposed AFPM motor consumes about $15 \%$ less energy than motors designed using traditional methods.
\end{abstract}

Keywords: electric vehicle; axial-flux permanent-magnet (AFPM) motor; driving scenario; optimization

\section{Introduction}

Increasing concerns about the natural environment and growing shortages of petroleum resources have driven many researchers to develop electric vehicles (EV). Due to a wide range of variable driving circumstances, such as load and vehicle speed, the operating point of a motor constantly changes. The working area of the motor, which matches a driving scenario involving accelerating, cruising, and slope climbing, is the main requirement for motor design.

EV motors are traditionally designed to satisfy the basic requirements of rated or maximum power, torque, and speed based on the driving conditions of acceleration and speed. For example, Kahourzade et al. [1] discussed a comprehensive design of a 10-kW axial-flux permanent-magnet (AFPM) motor for an EV direct drive based on the power and torque requirement. Lindh et al. [2] designed an interior permanent-magnet synchronous motor (PMSM) for traction application to meet the requirements of torque and speed (TN) under the constraints of voltage and current using an optimization process; however, the resulting torque and speed curve was determined by tuning the number of turns, the torque, and the current ratio. One drawback of the traditional motor design is that a close relationship does not exist between the TN curve and the motor parameters.

A better design methodology could include a target $\mathrm{TN}$ curve with two operation zones: constant torque and constant power, under the constraints of motor drive. A third operation zone could be extended using the field-weakening control [3]. Qi et al. [4] developed a method for predicting the flux-weakening performance of permanent-magnet (PM) brushless alternating current $(\mathrm{AC})$ machines based on a $d$-q-axis flux linkage model in order to analyze the maximum working area of the TN curve using the finite element (FE) method. They formulated the TN equations in terms of motor 
parameters, such as PM flux, $d$ - $q$-axis inductances, and phase resistance, as well as driving voltage and current. A similar analysis method was used for switched-flux permanent-magnet (SFPM) machines [5]. Unfortunately, those formulas were not used to determine the motor parameters. Therefore, rough specifications of maximum torque, base speed, and maximum speed based on the TN curve only provide a rough baseline for designing a motor. It is very possible that this type of motor is either over-designed or under-designed, which would mean that the motor drive must be re-selected and tuned so that the motor can be integrated into the vehicle propulsion system. Furthermore, since an EV operates over a wide torque-speed range in response to various driving conditions, the motor design process should consider overall energy consumption. The high efficiency operating region of the current PM motors used in EVs is typically designed around either the rated operating point [6] or several frequent operating points [7]. To date, the integration of driving cycles into the design optimization of an electric driveline has received limited attention in the literature.

This paper proposes a novel approach for designing an AFPM motor for EVs. The design methodology is divided into four stages. First, a target TN curve based on a driving scenario, battery capabilities, motor drive pattern, and basic torque and voltage equations of the proposed motor is specified in Section 2. This target TN curve is closely related to the back electromotive force (EMF) constant, phase inductance, and phase resistance of the motor. Second, the magnetic circuit model with a quasi-3-dimensional (quasi-3D) motor configuration is provided in Section 3. Third, an optimal motor shape is determined using three objectives-minimizing motor weight, maximizing motor efficiency at the rated operating point, and minimizing energy loss (EL) over various driving cycles-as described in Section 4. Fourth, FE verification of the proposed motor is presented in Section 5. Finally, Section 6 presents the study's conclusions.

\section{Specifications and Target Torque and Speed Curve}

\subsection{Simplified Vehicle Model}

The proposed traction motor is designed for a four-wheel-drive passenger car weighing $1800 \mathrm{~kg}$. Each wheel radius of $0.317 \mathrm{~m}$ is driven by an AFPM motor with a planetary reduction gear of ratio 4:1. Figure 1a shows the schematic view of the vehicle, and Figure $1 \mathrm{~b}$ illustrates the vehicle parameters of a simplified vehicle model. For determining a target TN curve, only the equation of motion along the longitudinal axis of the vehicle is required:

$$
F_{\mathrm{f}}+F_{\mathrm{r}}-\left(R_{\mathrm{a}}+R_{\mathrm{rf}}+R_{\mathrm{rr}}+W \sin \theta\right)=\gamma \frac{W}{\mathrm{~g}} a
$$

where $F_{\mathrm{f}}$ and $F_{\mathrm{r}}$ are the tractive efforts of the front and rear tires, $R_{\mathrm{a}}$ is the aerodynamic drag, $R_{\mathrm{rf}}$ and $R_{\mathrm{rr}}$ are the rolling resistances of the front and rear tires, $W$ is the vehicle weight, $\gamma$ is the equivalent mass coefficient, and $a$ is the vehicle acceleration along the longitudinal axis.

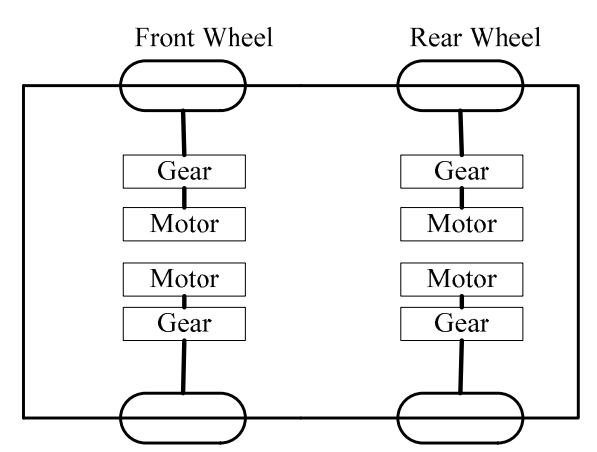

(a)

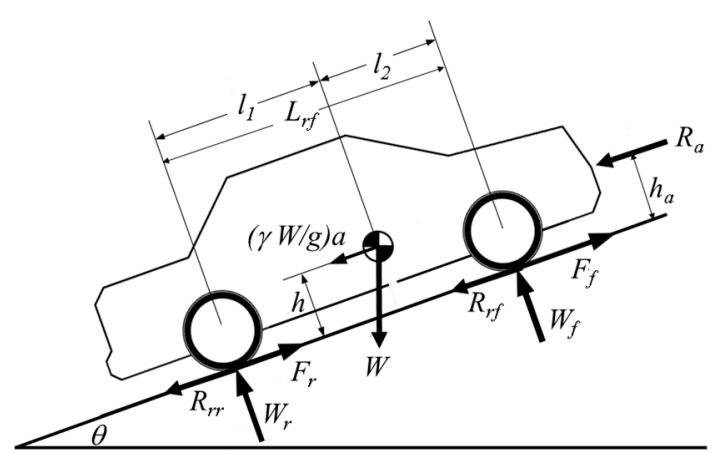

(b)

Figure 1. (a) A schematic view of a four-wheel-drive electric passenger car; and (b) the half vehicle model. 
By assuming that the two front motors share the same torque as the two rear motors, the front and rear tractive efforts between the tire and ground without slipping are equal and expressed as:

$$
F_{\mathrm{f}}=F_{\mathrm{r}}=\frac{2 T \eta \kappa}{r}
$$

where $T$ is the motor's tractive torque, $r$ is the wheel radius, $\eta$ is the mechanical efficiency, and $\kappa$ is the gear ratio. The aerodynamic drag $R_{\mathrm{a}}$ is expressed as:

$$
R_{\mathrm{a}}=\frac{\rho}{2} C_{\mathrm{D}} A_{\mathrm{f}} V_{\mathrm{r}}^{2}
$$

where $\rho$ is the air mass density, $C_{\mathrm{D}}$ is the coefficient of aerodynamic resistance, $A_{\mathrm{f}}$ is the frontal area of the vehicle, and $V_{\mathrm{r}}$ is the speed of the vehicle relative to the wind.

When the height of the point of application of aerodynamic drag $h_{\mathrm{a}}$ is assumed to be near the height of vehicle's mass center $h$, the normal forces on the front and rear wheels are, respectively, expressed as:

$$
\begin{aligned}
W_{\mathrm{f}} & =\frac{W l_{2} \cos \theta-h\left(R_{\mathrm{a}}+\gamma W a / \mathrm{g} \pm W \sin \theta\right)}{L_{\mathrm{rf}}} \\
W_{\mathrm{r}} & =\frac{W l_{1} \cos \theta-h\left(R_{\mathrm{a}}+\gamma W a / \mathrm{g} \pm W \sin \theta\right)}{L_{\mathrm{rf}}}
\end{aligned}
$$

where $l_{1}$ and $l_{2}$ are the distances between the center of mass of the vehicle and the front and rear axles, respectively, and $L_{\mathrm{rf}}$ is the wheelbase. Therefore, the rolling resistances $R_{\mathrm{rf}}$ and $R_{\mathrm{rr}}$ on the front and rear tires are given by:

$$
R_{\mathrm{rf}}=f_{\mathrm{r}} W_{\mathrm{f}} \text { and } R_{\mathrm{rr}}=f_{\mathrm{r}} W_{\mathrm{r}}
$$

where $f_{\mathrm{r}}$ is the rolling resistance factor. By neglecting the vehicle suspension forces, the total rolling resistance becomes $f_{\mathrm{r}} W \cos \theta$. The tractive torque $T$ and motor speed $\omega$ are expressed as:

$$
\begin{gathered}
T=\frac{r}{4 \eta \kappa}\left(\gamma m a+\frac{\rho}{2} C_{\mathrm{D}} A_{\mathrm{f}} V_{\mathrm{r}}^{2}+f_{\mathrm{r}} m \mathrm{~g} \cos \theta+m \mathrm{~g} \sin \theta\right) \\
\omega=\frac{v}{r\left(1-\lambda_{\mathrm{w}}\right)}
\end{gathered}
$$

where $v$ is the vehicle speed, and $\lambda_{\mathrm{w}}$ is the slip between the wheel and the road. Detailed vehicle parameters are provided in Table 1.

Table 1. Vehicle parameters and motor specifications. DC: direct current.

\begin{tabular}{ccc}
\hline Parameter (Unit) & Symbol & Value \\
\hline Radius of wheels $(\mathrm{m})$ & $r$ & 0.317 \\
Vehicle mass $(\mathrm{kg})$ & $m$ & 1800 \\
Equivalent mass coefficient & $\gamma$ & 1.08 \\
Gravitational acceleration $\left(\mathrm{m} / \mathrm{s}^{2}\right)$ & $\mathrm{g}$ & 9.81 \\
Rolling resistance factor & $f_{\mathrm{r}}$ & 0.013 \\
Air mass density $\left(\mathrm{kg} / \mathrm{m}^{3}\right)$ & $\rho$ & 1.225 \\
Aerodynamic coefficient & $\mathrm{C}_{\mathrm{D}}$ & 0.28 \\
Frontal area of the vehicle $\left(\mathrm{m}^{2}\right)$ & $A_{\mathrm{f}}$ & 1.6 \\
Gear ratio & $\mathrm{K}$ & $4: 1$ \\
Maximum DC voltage $(\mathrm{V})$ & $V_{\mathrm{DC}}$ & 380 \\
Maximum motor output power $(\mathrm{kW})$ & $P_{\mathrm{m}}$ & 20.4 \\
\hline
\end{tabular}

\subsection{Driving Scenario}

A novel design methodology is proposed based on the driving scenario and the motor's torque, speed, and power performance boundaries. The motor's target TN curve is then determined using 
battery specifications and motor drive properties. Three driving scenarios were determined before the motor was designed: (1) the maximum slope that the vehicle can ride at a low speed is $35 \%$; (2) the vehicle can provide maximum acceleration under $40 \mathrm{~km} / \mathrm{h}$; and (3) the maximum cruise speed on a road with a $5 \%$ slope is $120 \mathrm{~km} / \mathrm{h}$. The torque production required by the motor was obtained as a function of the vehicle speed and the road slope, which are shown as dotted lines on the TN coordinates presented in Figure 2. The required maximum motor torque is about $133.2 \mathrm{Nm}$ at point $\mathrm{A}$ for the vehicle riding on a road with a maximum slope of $35 \%$ at a very low speed. The maximum output power, $P_{\mathrm{m}}=20.4 \mathrm{~kW}$, of the motor is then required in order for the vehicle to reach the speed of $40 \mathrm{~km} / \mathrm{h}$ at point $\mathrm{B}$. According to the thermal constraint, the continuous motor torque is set as half of the maximum torque. The continuous motor power, $P_{\mathrm{c}}=13.4 \mathrm{~kW}$, is a hyperbolic curve, while the maximum motor speed occurs at point $C$ for the vehicle cruising at its maximum speed of $120 \mathrm{~km} / \mathrm{h}$ on a $5 \%$ slope (approximate motor speed $\omega_{\mathrm{c}}=4094 \mathrm{rpm}$ ). Here, the maximum and continuous TN curves set the performance requirement of a motor for an EV.

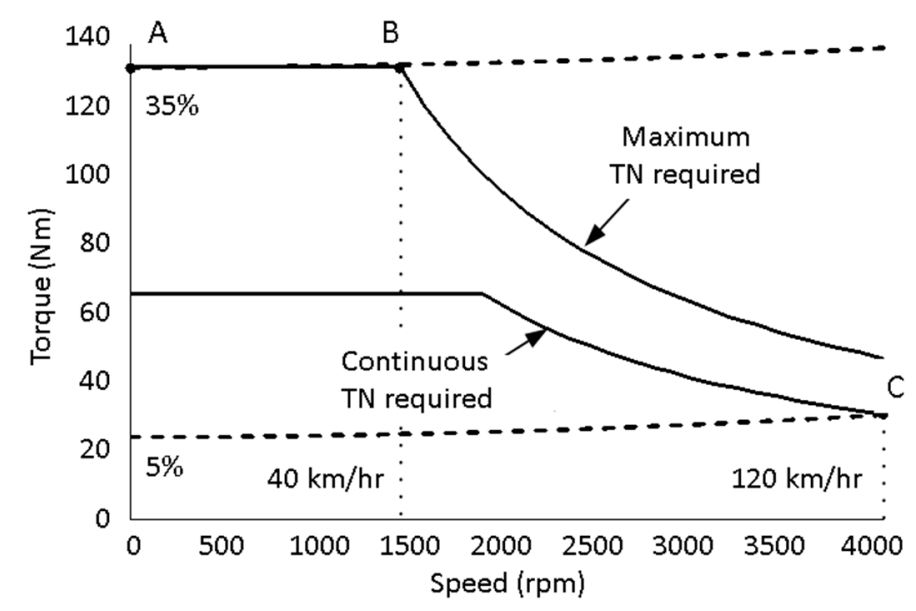

Figure 2. Torque and speed (TN) curve requirement for one motor.

\subsection{Motor Equations}

The two-axis voltage equations of a PM motor at the steady-state sinusoidal operation are usually expressed as:

$$
\begin{gathered}
V_{\mathrm{d}}=R_{\mathrm{ph}} i_{\mathrm{d}}-L_{\mathrm{q}} i_{\mathrm{q}} N_{\mathrm{p}} \omega \\
V_{\mathrm{q}}=R_{\mathrm{ph}} i_{\mathrm{q}}+L_{\mathrm{d}} i_{\mathrm{d}} N_{\mathrm{p}} \omega+K_{\mathrm{e}} \omega
\end{gathered}
$$

where $V_{\mathrm{d}}, V_{\mathrm{q}}, i_{\mathrm{d}}, i_{\mathrm{q}}, L_{\mathrm{d}}$, and $L_{\mathrm{q}}$ are the $d$-q-axis voltages, currents, and inductance, respectively; $K_{\mathrm{e}}$ is the back EMF constant of the motor; $R_{\mathrm{ph}}$ is the phase resistance; $\omega$ is the mechanical speed of the motor; and $N_{\mathrm{p}}$ is the number of pole pairs.

Because this motor has surface-mounted PMs, $L_{\mathrm{d}}$ and $L_{\mathrm{q}}$ can be assumed to be equal to the phase inductance $L_{\mathrm{ph}}$. When the peak of the sinusoidal phase current of the motor $I_{\mathrm{ph}}$ is fed on the $q$-axis, $i_{\mathrm{d}}=0$ and $i_{\mathrm{q}}=I_{\mathrm{ph}}$. The torque equation is simply expressed as:

$$
T=\frac{3 K_{\mathrm{e}} V_{\mathrm{ph}}}{2 R_{\mathrm{ph}}} \frac{-\frac{K_{\mathrm{e}} \omega}{V_{\mathrm{ph}}}+\sqrt{1+\left(\xi \frac{K_{\mathrm{e}} \omega}{V_{\mathrm{ph}}}\right)^{2}-\xi^{2}\left(\frac{K_{\mathrm{e}} \omega}{V_{\mathrm{ph}}}\right)^{4}}}{\left(\xi \frac{K_{\mathrm{e}} \omega}{V_{\mathrm{ph}}}\right)^{2}+1}
$$

where $\xi=\left(N_{\mathrm{p}} L_{\mathrm{ph}} V_{\mathrm{ph}}\right) /\left(R_{\mathrm{ph}} K_{\mathrm{e}}\right)$. When $Y=T\left(2 R_{\mathrm{ph}}\right) /\left(3 K_{\mathrm{e}} V_{\mathrm{ph}}\right)$ and $X=\omega / \omega \max =\omega\left(K_{\mathrm{e}} / V_{\mathrm{ph}}\right)$, we obtain an equality:

$$
X+Y=\sqrt{1+\xi^{2} X^{2}-\xi^{2} X^{4}}-\xi^{2} X^{2} Y
$$


Figure 3 shows the curves of $Y$ as a function of $X$ for various $\xi$ with a constant $V_{\mathrm{ph}}$. The $Y X$ curves, or the equivalently dimensionless TN curves without current limit, are concave toward the origin. When $\xi$ approaches zero, the phase inductance $L_{\mathrm{ph}}$ is much smaller than the phase resistance $R_{\mathrm{ph}}$, which is true for most motors, and the $Y X$ curve converges to a straight line as $\xi$ approaches zero at a low electric motor speed. A more precise TN curve will be created by the torque and electric equations of the motor, voltage, and current limits of the power source, and the modulation method of the motor drive.

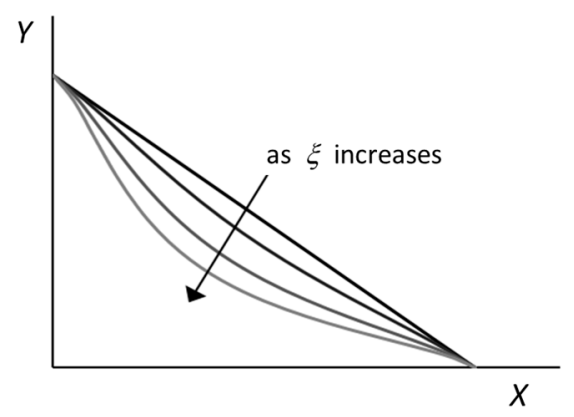

Figure 3. Dimensionless TN curves without current limit.

\subsection{Target Torque and Speed Curves with Three Operation Zones}

The TN curve of the motor can be specified by three operation zones: zone I, constant torque; zone II, maximum direct current (DC); and zone III, maximum voltage, shown as the thin solid curve A- $p-q-\mathrm{C}$ in Figure 4. All of the operation points on any one of the TN curves must satisfy the equations presented below through the assumptions that (1) the motor inductance is neglected, (2) the power conversion between the DC and three-phase terminals is conserved, (3) the three-phase voltages are constructed using space-vector pulse-width modulation (SVPWM), and (4) the peak of the sinusoidal phase current of the motor $I_{\mathrm{ph}}$ is applied to the $q$-axis, $i_{\mathrm{d}}=0$ and $i_{\mathrm{q}}=I_{\mathrm{ph}}$, without considering the field weakening control.

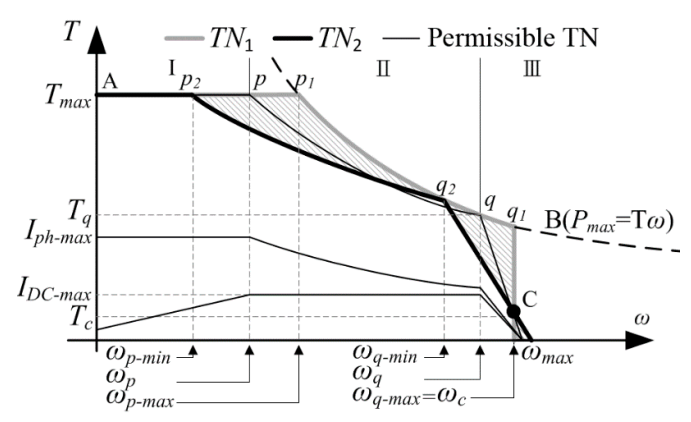

Figure 4. Target TN curve, its corresponding DC and phase currents, and two boundaries of the TN curves.

(A) Phase voltage and DC voltage modulation equation:

$$
V_{\mathrm{ph}}=\frac{1}{\sqrt{3}} M_{\mathrm{i}} V_{\mathrm{DC}}
$$

where $V_{\mathrm{ph}}$ is the peak of sinusoidal phase voltage of the motor; $V_{\mathrm{DC}}$ is the voltage of the DC source; and $M_{\mathrm{i}}$ is a modulation index which is positive but less than 1 [8].

(B) Phase current and DC current modulation equation:

$$
I_{\mathrm{DC}}=\frac{\sqrt{3}}{2} M_{\mathrm{i}} I_{\mathrm{ph}}
$$


where $I_{D C}$ is the current of the DC source. It is assumed that Equations (13) and (14) satisfy the power conversion in the form of $V_{\mathrm{ph}} I_{\mathrm{ph}}=(2 / 3) V_{\mathrm{DC}} I_{\mathrm{DC}}$.

(C) Motor torque equation:

$$
T=\frac{3}{2} K_{\mathrm{e}} I_{\mathrm{ph}}
$$

where $T$ is the torque production of a three-phase motor driven by sinusoidal currents, each with a phase angle of $120^{\circ} \mathrm{E}$.

(D) Steady-state electrical equation:When the phase current is fed in phase with the back EMF wave and the motor inductance is neglected, voltage Equations (9) and (10) with $i_{\mathrm{d}}=0$ become:

$$
V_{\mathrm{ph}}=R_{\mathrm{ph}} I_{\mathrm{ph}}+K_{\mathrm{e}} \omega
$$

During the constant torque, zone $\mathrm{I}$, the maximum torque $T_{\max }$ is produced at the maximum phase current $I_{\mathrm{ph} \text {-max }}$, and the phase voltage $V_{\mathrm{ph}}$ is controlled by a modulation index $M_{\mathrm{i}}$ so that $T_{\max }=(3 / 2) K_{\mathrm{e}} I_{\mathrm{ph}-\max }$ over the speed range of $\left[0, \omega_{\mathrm{p}}\right]$. It is assumed that no power is lost during the power conversion, and the current drawn from the DC terminal increases linearly with respect to the motor speed, according to Equation (14), where $M_{\mathrm{i}}$ is adjusted from $M_{\min }$ to $M_{1}$. The minimum modulation index $M_{\min }$ occurs when $\omega=0$, and it is calculated by Equations (13) and (16); whereas, $M_{1}$ is calculated by Equations (14) and (15) when the maximum DC current $I_{\mathrm{DC}-\max }$ is drawn from the power source at $\omega=\omega_{\mathrm{p}}$. The maximum motor speed $\omega_{\mathrm{p}}$ of zone $\mathrm{I}$ is then calculated using Equations (13)-(16), and is expressed as:

$$
\omega_{\mathrm{p}}=\left[\frac{\sqrt{M_{1}^{2}+\left(\xi M_{\min }\right)^{2}\left(M_{1}^{2}-M_{\min }^{2}\right)}-M_{\min }}{1+\left(\xi M_{\min }\right)^{2}}\right] \omega_{\max }
$$

Beyond $M_{i}=M_{1}$, the motor operates at the maximum DC current $I_{\mathrm{DC} \text {-max }}$ in zone II. The phase voltage and current are adjusted from $M_{1}$ until it increases to its maximum value 1 , so that the phase voltage $V_{\mathrm{ph}}$ is not constant but a function of motor speed. The modulation index $M_{1}$ is calculated using Equations (14) and (15). The relationship between TN is derived from Equations (13)-(16) and is expressed as:

$$
T\left[\frac{\omega}{2 V_{\mathrm{DC}} I_{\mathrm{DC}}}+\sqrt{\left(\frac{\omega}{2 V_{\mathrm{DC}} I_{\mathrm{DC}}}\right)^{2}+\frac{2}{3} \frac{R_{\mathrm{ph}}}{V_{\mathrm{DC}} I_{\mathrm{DC}} K_{\mathrm{e}}^{2}}}\right]=1
$$

where $I_{\mathrm{DC}}=I_{\mathrm{DC}-\max }$. It is interesting to note that Equation (11) was approximated to a straight line when the inductance was zero $(\xi=0)$, but Equation (18) is a parabola with the same assumption that the inductance is zero. This is because that the $V_{\mathrm{ph}}$ in Equatin (18) was varying as a function of modulation index in the range between $\left[M_{1}, 1\right]$ in zone II, while the $V_{\mathrm{ph}}$ in Equation (11) was a constant. The maximum motor speed $\omega_{\mathrm{q}}$ of zone II is then calculated using Equations (13)-(16), and is expressed as:

$$
\omega_{\mathrm{q}}=\left[\frac{\sqrt{1+\left(\xi M_{1} M_{\min }\right)^{2}\left(1-M_{1}^{2} M_{\min }^{2}\right)}-M_{1} M_{\min }}{1+\left(\xi M_{1} M_{\min }\right)^{2}}\right] \omega_{\max }
$$

In zone III, the motor operates at the maximum phase voltage $V_{\mathrm{ph}}=V_{\mathrm{DC}} / \sqrt{3}$. The relationship between torque and the speed higher than $\omega_{\mathrm{q}}$ is approximated by a straight line, which is derived by Equation (11) for $\xi=0$ as the inductance is neglected. This line also passes the maximum motor speed point $C$, as shown in Figure 4, and is expressed as:

$$
T=-\frac{3}{2} \frac{K_{\mathrm{e}}^{2}}{R_{\mathrm{ph}}}\left(\omega-\omega_{\mathrm{c}}\right)+T_{\mathrm{c}}
$$

where $T_{\mathrm{c}}$ is the torque required for the motor at the maximum speed $\omega_{\mathrm{c}}$ on a slope of $5 \%$. 


\subsection{Boundaries of the Torque and Speed Curves}

In Equation (18), the motor torque is a function of phase resistance and the back EMF constant, and there might be infinite sets of TN curves that satisfy the driving scenario and the motor and drive properties. The boundaries of the TN curves are determined by assuming extreme conditions. When the phase inductance $L_{\mathrm{ph}}$ is negligibly small, the TN curve can be approximated by a straight line between $\left(3 K_{\mathrm{e}} V_{\mathrm{ph}} / 2 R_{\mathrm{ph}}, 0\right)$ and $\left(0, V_{\mathrm{ph}} / K_{\mathrm{e}}\right)$, which is also shown in Figure 3 for $\xi=0$. In the extreme case of $R_{\mathrm{ph}}=\varepsilon(0<\varepsilon<<1)$, the straight line becomes perpendicular to the speed axis, so that the maximum value of corner speed $\omega_{\mathrm{q}-\max }$ is equal to $\omega_{\mathrm{c}}$. The corresponding back EMF constant of this vertical line has a maximum value:

$$
K_{\mathrm{e}-\max }=\frac{V_{\mathrm{DC}}}{\sqrt{3} \omega_{\mathrm{c}}}
$$

this vertical boundary connects the hyperbola $P_{\max }=T \omega$ at $q_{1}$ and intersects the maximum torque line at $p_{1}$ in zone I. Here, we complete the first boundary curve $T N_{1}$ which links A- $p_{1}-q_{1}-\mathrm{C}$.

The other boundary of the TN curves is determined under the constraint of the maximum DC current $I_{\mathrm{DC}-m a x}$ supplied by the battery in zone II and zone III. By assuming $L_{\mathrm{ph}}=0$ for zone III, where $M_{\mathrm{i}}=1$, the maximum phase resistance allowed for the motor to operate at its maximum power $P_{\max }=T \omega$ is obtained by:

$$
R_{\mathrm{ph}-\max }=\frac{V_{\mathrm{DC}} I_{\mathrm{DC}-\max }-P_{\max }}{2 I_{\mathrm{DC}-\max }^{2}}
$$

From Equations (13), (14) and (16), the maximum motor speed $\omega_{\max }$ in zone III (Figure 4) is expressed as $V_{\mathrm{DC}} / \sqrt{3} K_{\mathrm{e}}$ as $I_{\mathrm{DC}}$ and $T$ approaching 0 . Substituting these values into Equation (20) gives the relationship between $R_{\mathrm{ph}}$ and $K_{\mathrm{e}}$ as:

$$
3 \omega_{\mathrm{c}} K_{\mathrm{e}}^{2}-\sqrt{3} V_{\mathrm{DC}} K_{\mathrm{e}}+2 T_{\mathrm{c}} R_{\mathrm{ph}}=0
$$

The minimum $K_{\mathrm{e}-\min }$ is obtained by substituting $R_{\mathrm{ph}-\max }$ into Equation (23), and this determines the slope of line Equation (20) in zone III. This straight line intersects with curve B at $q_{2}$, and the hyperbola Equation (18) with the same $K_{\mathrm{e}-\mathrm{min}}$ and $R_{\text {ph-max }}$ in zone II connects the constant torque curve in zone I at $p_{2}$. Here, we complete the second boundary curve $T N_{2}$, which links A- $p_{2}-q_{2}-\mathrm{C}$.

All the TN curves in the ranges of $K_{\mathrm{e}-\min }<K_{\mathrm{e}}<K_{\mathrm{e}-\text { max }}$ and $R_{\mathrm{ph} \text {-min }}<R_{\mathrm{ph}}<R_{\mathrm{ph} \text {-max }}$ satisfy the three driving scenarios. By using the driving parameters and constraints given in Table 1 , the boundary $\mathrm{TN}$ curves and their corresponding motor and drive parameters are calculated and illustrated in Table 2.

Table 2. Motor and drive parameters for the TN boundaries.

\begin{tabular}{c|c|c|c|c}
\hline Boundary & \multicolumn{2}{|c|}{$T N_{\mathbf{1}}$} & \multicolumn{2}{c}{$T N_{\mathbf{2}}$} \\
\hline$K_{\mathrm{e}}(\mathrm{V} / \mathrm{rad} / \mathbf{s})$ & $K_{\mathrm{e}-\max }$ & 0.512 & $K_{\mathrm{e}-\min }$ & 0.441 \\
\hline $\boldsymbol{R}_{\mathrm{ph}}(\Omega)$ & $R_{\mathrm{ph}-\min }$ & $\varepsilon(0<\varepsilon<<1)$ & $R_{\mathrm{ph}-\max }$ & 0.641 \\
\hline$\omega_{\max }(\mathbf{r p m})$ & \multicolumn{2}{|c|}{$4094\left(=\omega_{\mathrm{c}}\right)$} & \multicolumn{2}{c}{4884} \\
\hline $\boldsymbol{I}_{\mathrm{DC}-\max }(\mathbf{A})$ & \multicolumn{2}{|c|}{70.4} & \multicolumn{2}{c}{201.8} \\
\hline $\boldsymbol{I}_{\mathrm{ph}-\max }(\mathrm{A})$ & \multicolumn{2}{|c|}{173.5} & $\omega_{\mathrm{p}-\min }$ & 631 \\
\hline$\omega_{\mathbf{p}}(\mathbf{r p m})$ & $\omega_{\mathrm{p}-\max }$ & 1918 & $\omega_{\mathrm{q}-\min }$ & 3225 \\
\hline$\omega_{\mathrm{q}}(\mathbf{r p m})$ & $\omega_{\mathrm{q}-\max }$ & 4094 & $T_{\mathrm{q} 2}$ & 60.40 \\
\hline$T_{\mathbf{q}}(\mathbf{N m})$ & $T_{\mathrm{q} 1}$ & 47.58 &
\end{tabular}

\section{Quasi-3-Dimensional Magnetic Circuit Model}

All of the design parameters of the AFPM motor shown in Figure 5a for the EV are presented in Table 3. It is approximately to slice the AFPM motor into rings of different radii, and each ring is extended as a 2-dimensional (2D) linear machine, as shown in Figure 5b [9]. Figure 5c shows a 
cross-section of each ring of the AFPM motor along a circumference of a radius ranging between $R_{\mathrm{o}}$ and $R_{\mathrm{i}}$. The circumferential coordinate is denoted by $x$.

Table 3. Design parameters.

\begin{tabular}{cccc}
\hline Parameter & Symbol & Parameter & Symbol \\
\hline Inner radius & $R_{\mathrm{i}}$ & Slot width & $w_{\mathrm{s}}$ \\
Outer radius & $R_{\mathrm{o}}$ & Slot height & $d_{\mathrm{s}}$ \\
Stator back iron thickness & $h_{\mathrm{sb}}$ & Shoe height & $h_{\mathrm{s}}$ \\
Rotor back iron thickness & $h_{\mathrm{rb}}$ & Slot opening & $w_{\mathrm{so}}$ \\
Air-gap length & $g$ & Magnet length & $l_{\mathrm{m}}$ \\
Number of slots & $N_{\mathrm{s}}$ & Magnet gap & $w_{\mathrm{pmg}}$ \\
Number of poles & $N_{\mathrm{m}}$ & No. of turns & $N$ \\
\hline
\end{tabular}
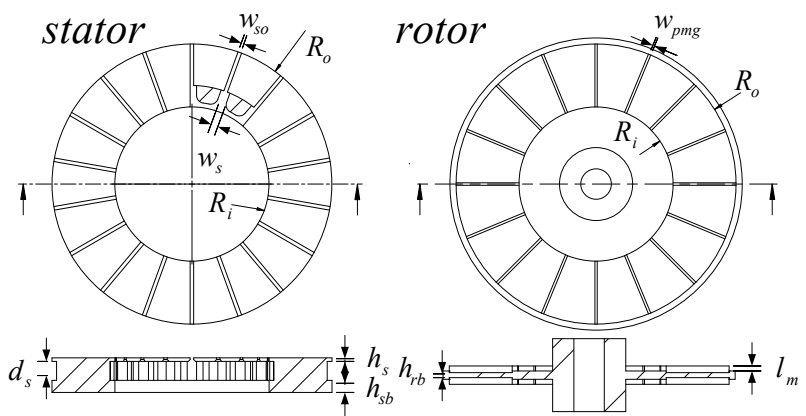

(a)

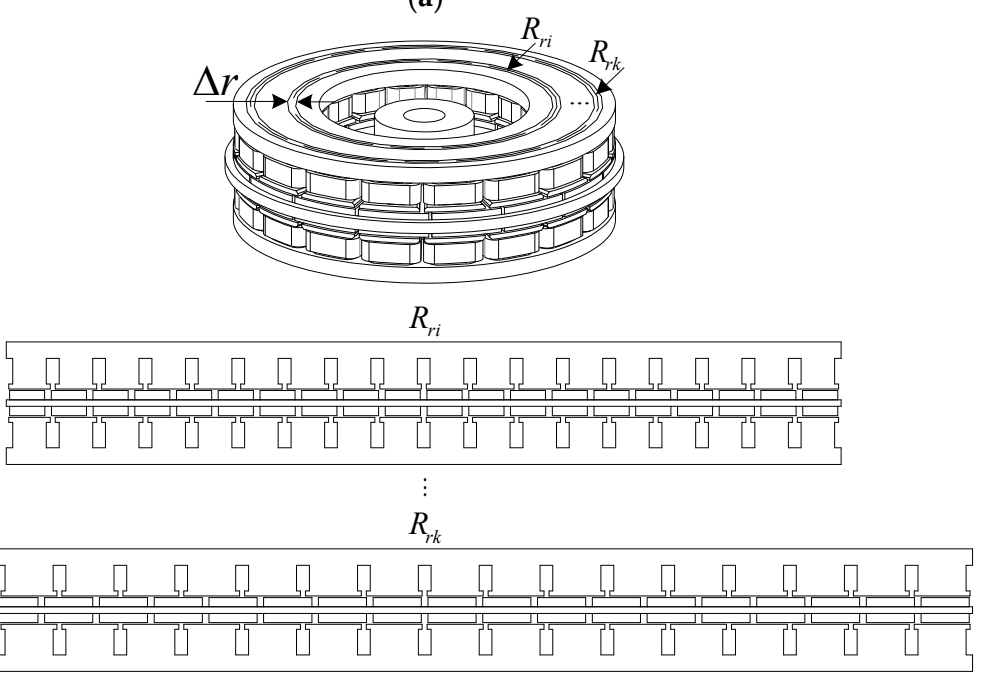

(b)

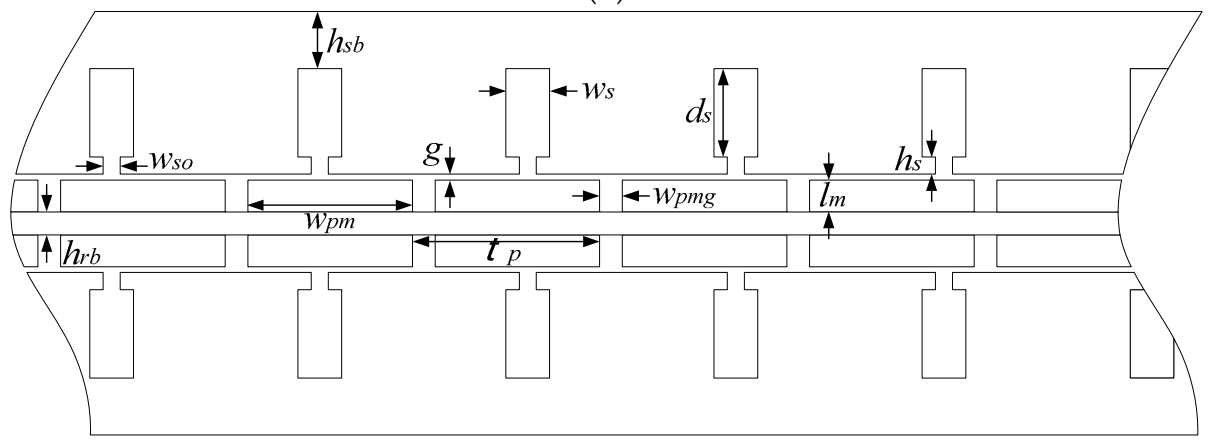

(c)

Figure 5. (a) Geometry of stator and rotor; (b) geometry of quasi-3-dimensional (quasi-3D) magnetic circuit model; and (c) 2-dimensional (2D) cross-sectional view. 
It is assumed that there is no fringing effect and no magnetic flux in the radial direction, so that each of the linear machines is independent. The overall performance of an AFPM motor will be the sum of the performance of all of the linear machines when a linear magnetic property is assumed in the following magnetic circuit analysis. The air-gap flux density distribution for slotless configuration is adopted from [10]:

$$
B_{\mathrm{pm}}(x)=\sum_{n=1,3,5, \ldots}^{\infty} \frac{-\frac{8 B_{\mathrm{r}}}{n \pi} \sin \left(\frac{\alpha_{\mathrm{p}} n \pi}{2}\right) \exp \left(\frac{n \pi g}{\tau_{\mathrm{p}}}\right)\left(\exp \left(\frac{n \pi l_{\mathrm{m}}}{\tau_{\mathrm{p}}}\right)-1\right) \cos \left(\frac{n \pi}{\tau_{\mathrm{p}}} x\right)}{\left(1+\mu_{\mathrm{R}}\right)\left(1-\exp \left(\frac{2 n \pi\left(g+l_{\mathrm{m}}\right)}{\tau_{\mathrm{p}}}\right)\right)+\left(1-\mu_{\mathrm{R}}\right)\left(\exp \left(\frac{2 n \pi g}{\tau_{\mathrm{p}}}\right)-\exp \left(\frac{2 n \pi l_{\mathrm{m}}}{\tau_{\mathrm{p}}}\right)\right)}
$$

where $B_{\mathrm{r}}$ is the remanence flux density and $\alpha_{\mathrm{p}}$ is the ratio between the magnet width $w_{\mathrm{pm}}$ and the pole pitch $\tau_{\mathrm{p}}$. As the rotor rotates, the relative position of the rotor and stator, which is defined as the rotor shift $s$, varies, and the air-gap flux density is not only a function of peripheral coordinate $x$ but also a function of rotor shift $s$. By considering the stator slotting effect, the air-gap flux density must be reduced by additional air-gap reluctance. The air-gap flux density distribution function is then modified as:

$$
B_{\mathrm{g}}(x, s)=\Pi(x) B_{\mathrm{pm}}(x-s)
$$

where $\Pi(x)$ is the relative permeance, which is defined as the ratio between the equivalent air gap with and without slots, as follows:

$$
\Pi(x)=\frac{\frac{l_{\mathrm{m}}}{\mu_{\mathrm{R}}}+g}{\frac{l_{\mathrm{m}}}{\mu_{\mathrm{R}}}+g_{\mathrm{e}}(x)}
$$

where $g_{\mathrm{e}}$ is the effective air-gap length and $\mu_{\mathrm{R}}$ is the recoil permeability of the magnet [11].

This air-gap flux density distribution is compared with the result obtained from the 2D FE method for an example of $s=0^{\circ} \mathrm{E}$, as shown in Figure 6a. In the FE analysis, the flux density becomes high near the fringe of the slot (location a) because of the flux saturation that was not modeled on the vertex of the stator teeth in the magnetic circuit model. A modeling error near the center of the slot (location b) also causes modeling errors in the preliminary motor design. The corresponding flux linkage of phase A is calculated, and it matches very well with the value obtained using the 2D FE method, as shown in Figure $6 b$.

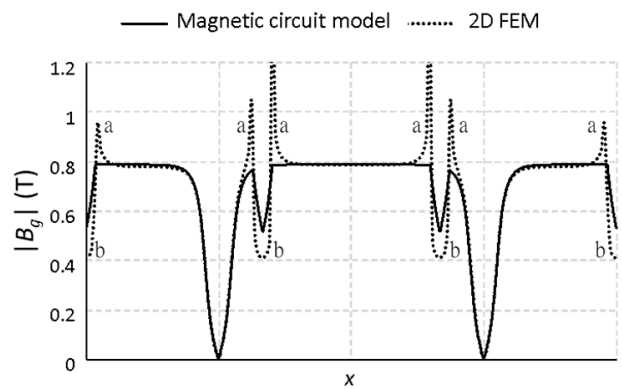

(a)

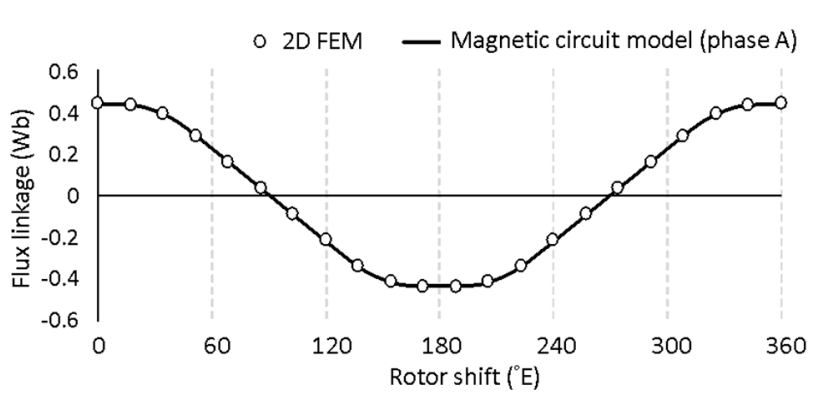

(b)

Figure 6. (a) Comparison of the air-gap flux density distributions between the analytical and 2D finite element $(\mathrm{FE})$ methods $\left(s=0^{\circ} \mathrm{E}\right)$; and $(\mathbf{b})$ comparison of the flux linkage of phase A between the analytical and 2D FE methods.

Azzouzi et al. [12] presented an interesting approach that allows us to consider the fringing effect. From the 2D FE analysis, the air-gap flux density distribution in the radial direction $(r)$ is illustrated in Figure 7a. Therefore, a dimensionless fringing-effect coefficient $\Lambda(r)=B_{\mathrm{z}} / B_{\mathrm{z} \text {-maz }}$ is calculated, as shown in Figure $7 \mathrm{~b}$, where $B_{z}(r)$ is the air-gap flux density function in the radial direction and its maximum value $B_{z-m a x}$ occurs in the middle range between $R_{\mathrm{o}}$ and $R_{\mathrm{i}}$. As $\left(R_{\mathrm{o}}-R_{\mathrm{i}}\right)$ increases, the fringing-effect coefficient increases near $R_{\mathrm{i}}$ and $R_{\mathrm{o}}$. Thus, the air-gap flux density distribution function in Equation (25) is modified as:

$$
B_{\mathrm{g}}^{\prime}(r, x, s)=\Lambda(r) \Pi(x) B_{\mathrm{pm}}(x-s)
$$




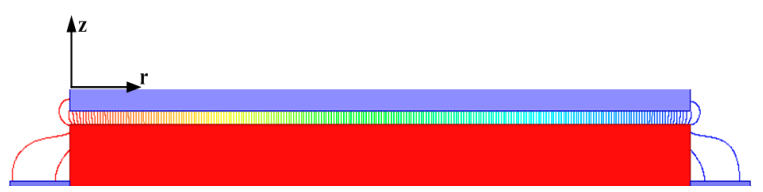

(a)

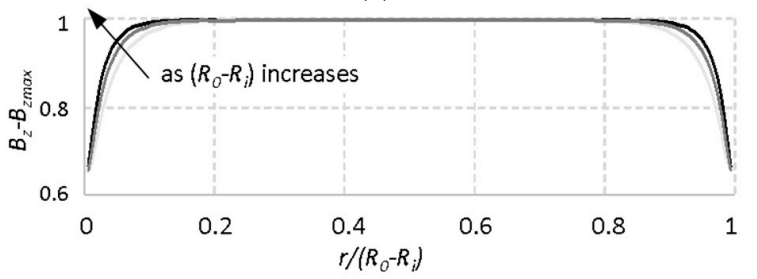

(b)

Figure 7. (a) Flux density distribution from the 2D FE analysis; and (b) the dimensionless fringing-effect coefficient along the radial coordinate for various $\left(R_{\mathrm{O}}-R_{\mathrm{i}}\right)$.

\section{Motor Sizing and Optimization}

\subsection{Motor Sizing}

Ishak et al. [13] found that if a motor had a similar number of slots and poles with a relationship of $N_{s}=N_{\mathrm{m}} \pm 2$, then it would provide high torque with a high winding factor and a low torque ripple. In addition, a higher number of pole pairs could cause the motor to have shorter end windings and a lighter weight, but that might result in a larger radius and higher core loss at a high electric frequency. According to the AFPM motor parameters presented in Table 2, the motors with slot and pole combinations of $12 / 14,18 / 16$, and $18 / 20$, which are simply referred to the $12 / 14$ motor, the $18 / 16$ motor, and the $18 / 20$ motor, have satisfactory winding factors of $0.933,0.945$, and 0.945 , respectively, and they are promising candidates for the following optimal design.

As shown in Table 3,14 design parameters need to be determined. It is necessary to begin the sizing by assigning reasonable values to the independent design parameters, such as the air-gap length $\mathrm{g}$, the magnet gap $w_{\mathrm{pmg}}$, and the shoe height $h_{\mathrm{s}}$. Most of the other parameters are dependent variables, and they are determined by the motor geometry and performance equations so that the design targets of $K_{\mathrm{e}}$ and $R_{\mathrm{ph}}$ are satisfied. Through the process of calculating the size of the motor [14], three sets of motors, a 12/14 motor, an 18/16 motor, and an 18/20 motor, were obtained by changing different active parameters - the magnet length $l_{\mathrm{m}}$, the outer radius $R_{\mathrm{o}}$, and the inner radius $R_{\mathrm{i}}$, within a reasonable range.

\subsection{Multi-Objective Optimization}

The AFPM motor is designed to minimize energy consumption based on the motor weight and the frequent operating points of a driving cycle. The best motor size set is then determined using the following three design objectives or performance indices.

\subsubsection{Motor Weight}

The first design objective is to minimize the active motor weight that consists of the stator weight $W_{\mathrm{s}}$, the rotor weight $W_{\mathrm{r}}$, and the winding weight $W_{\mathrm{w}}$, which are all explicitly written in terms of the motor parameters shown in Table 3:

$$
\text { Min. } \quad W=W_{\mathrm{s}}+W_{\mathrm{r}}+W_{\mathrm{w}}
$$

\subsubsection{Energy Loss During the Driving Cycles}

The second motor design objective is for the EV to achieve a high driving efficiency over various driving cycles. Figure 8a shows three widely-used driving cycles: FTP-75, which is the Federal Test Procedure defined by the US Environmental Protection Agency; NEDC, which is known as New European Driving Cycle; and JC08, which is a new Japanese test cycle. The corresponding power loss and the equally sampled operation points on the TN map are, respectively, shown in Figure 8b,c. 


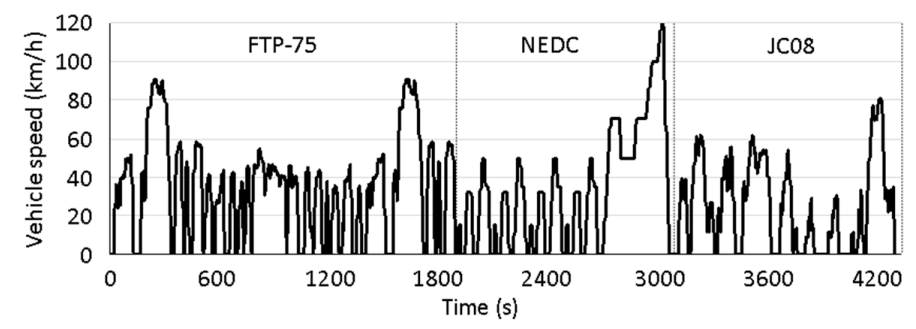

(a)

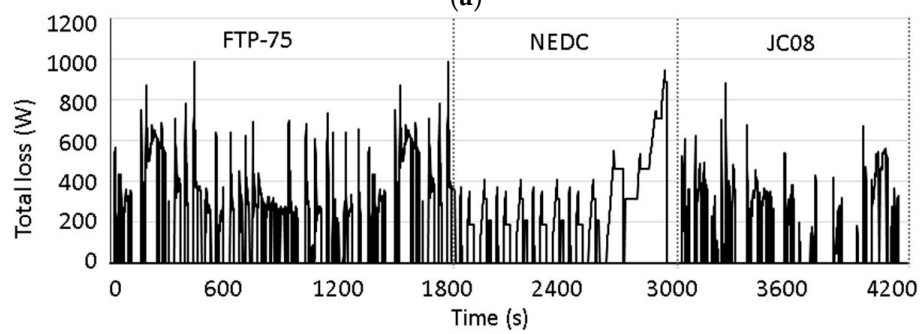

(b)

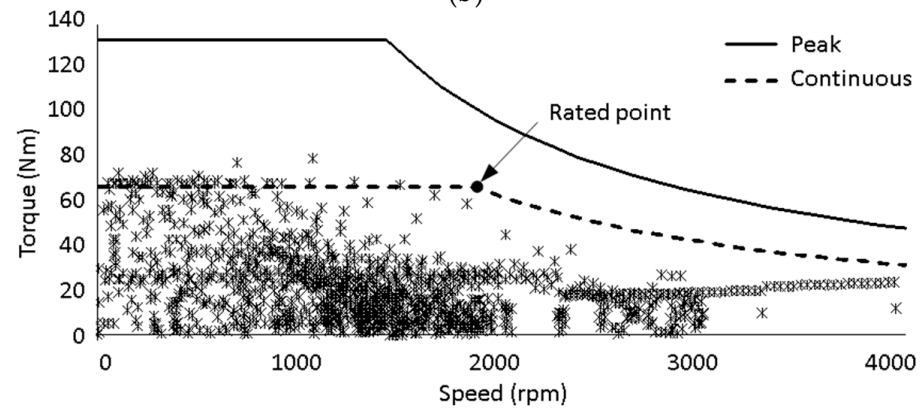

(c)

Figure 8. (a) The target driving cycles; (b) the power loss; and (c) the distribution of the corresponding operating points on the TN map.

The frequent operation points are scattered within the continuous TN curve; this implies that the motor can operate over the driving cycles without reaching a temperature limit. It is also important to note that the rated operation point at the corner speed is clearly not a high duty operation point during a typical driving cycle. Although the driving efficiency depends on various subsystems, such as the battery bank, the power inverter, the motor, the drive train gears, and the differentials, minimizing total EL of the motor is our major concern, and is formulated as follows:

$$
\text { Min. } \quad E L=\sum_{i=1}^{n}\left[k_{\mathrm{F}} P_{1, \mathrm{~F}}\left(\omega_{\mathrm{i}}, T_{\mathrm{i}}\right)+k_{\mathrm{N}} P_{1, \mathrm{~N}}\left(\omega_{\mathrm{i}}, T_{\mathrm{i}}\right)+k_{\mathrm{J}} P_{1, \mathrm{~J}}\left(\omega_{\mathrm{i}}, T_{\mathrm{i}}\right)\right] \Delta t
$$

where $E L$ is the total energy loss of the motor during the driving cycle; $P_{1, \mathrm{~F}}, P_{1, \mathrm{~N}}$, and $P_{1, \mathrm{~J}}$ are the power losses of the motor at the operation points of driving cycles FTP-75, NEDC, and JC08, respectively; and $\Delta t$ is the operation time interval. Different weighing factors, $k_{\mathrm{F}}, k_{\mathrm{N}}$, and $k_{\mathrm{J}}$, were assigned with the same value to address the same importance of the three driving cycles for the motor design. When minimal EL occurs, maximal driving-cycle efficiency has been achieved.

\subsubsection{Efficiency at the Rated Operation Point}

In order to compare the results of the proposed motor design with the traditional design method, only the efficiency of the rated operation point was maximized. The third design objective is written as the rated efficiency of the motor at the corner point, in Figure 8c, on the continuous TN curve:

$$
\text { Max. } \quad \eta_{\mathrm{r}}=\frac{T_{\mathrm{r}} \omega_{\mathrm{r}}}{T_{\mathrm{r}} \omega_{\mathrm{r}}+P_{\mathrm{r}}+P_{\mathrm{c}}+P_{\mathrm{s}}}
$$


where $\omega_{\mathrm{r}}$ is the rated speed, $T_{\mathrm{r}}$ is the rated torque, $P_{\mathrm{r}}$ is the core loss, $P_{\mathrm{c}}$ is the copper loss, and $P_{\mathrm{s}}$ is the stray loss. Here, the rated torque $T_{\mathrm{r}}$ is an implicit function of the design variables, and it is calculated using Equation (11) via analytical magnetic circuit models.

The compromise programming method in the multifunctional optimization system tool (MOST) [15] was applied to search for the optimal values of the design variables that maximize or minimize the above performance indices Equations (28)-(30). The optimizer MOST can deal with real, integer, and discrete design variables simultaneously. In this design, the performance indices, design functions, and prescribed constraints are expressed in terms of design variables, in which the number of winding layers and the number of turns per layer are integers; the wire diameter provided by the manufacturers is discrete, while the others are real. The computation flow of the gradient-based optimization algorithm in MOST is composed of: (1) initial guess of design variables, (2) calculation of gradients of objective and constraint functions, (3) determination of the maximum descent direction and the next set of design parameters, and (4) convergence test until reaching the final solution. During the optimization, different weighing factors were assigned to describe the different levels of importance of the three objectives. Table 4 illustrates the best five results from the multi-objective optimization process. While the $18 / 20$ motor was identified as the best result in four out of five cases, the $18 / 16$ motor is inferior to the other motors and it was abandoned.

Table 4. Multi-objective optimization results.

\begin{tabular}{|c|c|c|c|c|c|c|c|}
\hline \multicolumn{3}{|c|}{ Case } & 1 & 2 & 3 & 4 & 5 \\
\hline \multirow{5}{*}{ Weighing factor } & \multicolumn{2}{|c|}{ Motor weight $(W)$} & 0.7 & 0.85 & 0 & 0.8 & 0 \\
\hline & \multirow{3}{*}{ EL } & FTP-75 & 0.1 & 0.05 & $1 / 3$ & 0 & 0 \\
\hline & & NEDC & 0.1 & 0.05 & $1 / 3$ & 0 & 0 \\
\hline & & $\mathrm{JC} 08$ & 0.1 & 0.05 & $1 / 3$ & 0 & 0 \\
\hline & \multicolumn{2}{|c|}{ Rated efficiency $\left(\eta_{\mathrm{r}}\right)$} & 0 & 0 & 0 & 0.2 & 1 \\
\hline \multicolumn{2}{|c|}{ Number of slots } & $N_{\mathrm{s}}$ & 18 & 18 & 12 & 18 & 18 \\
\hline \multicolumn{2}{|c|}{ Number of poles } & $N_{\mathrm{m}}$ & 20 & 20 & 14 & 20 & 20 \\
\hline \multicolumn{2}{|c|}{ Outer radius (mm) } & $R_{\mathrm{o}}$ & 108 & 105 & 103 & 106 & 116 \\
\hline \multicolumn{2}{|c|}{ Inner radius $(\mathrm{mm})$} & $R_{\mathrm{i}}$ & 56 & 66 & 47 & 55 & 56 \\
\hline \multicolumn{2}{|c|}{ Magnet length (mm) } & $l_{\mathrm{m}}$ & 4.5 & 6.9 & 5.8 & 6.6 & 6.8 \\
\hline \multicolumn{2}{|c|}{ Slot height (mm) } & $d_{\mathrm{s}}$ & \multicolumn{5}{|c|}{16.2} \\
\hline \multicolumn{2}{|c|}{ Air-gap length (mm) } & $g$ & \multicolumn{5}{|c|}{1} \\
\hline \multicolumn{2}{|c|}{ Shoe height $(\mathrm{mm})$} & $\begin{array}{l}0 \\
h_{\mathrm{s}}\end{array}$ & \multicolumn{5}{|c|}{3.04} \\
\hline \multicolumn{2}{|c|}{ Stator back iron thickness (mm) } & $h_{\mathrm{sb}}$ & \multicolumn{5}{|c|}{6.3} \\
\hline \multicolumn{2}{|c|}{ Rotor back iron thickness (mm) } & $h_{\mathrm{rb}}$ & \multicolumn{5}{|c|}{4} \\
\hline \multicolumn{2}{|c|}{ Slot width $(\mathrm{mm})$} & $w_{\mathrm{S}}$ & \multicolumn{5}{|c|}{8.1} \\
\hline \multicolumn{2}{|c|}{ Magnet gap (mm) } & $w_{\text {pmg }}$ & \multicolumn{5}{|c|}{6} \\
\hline \multicolumn{2}{|c|}{ Slot opening $(\mathrm{mm})$} & $w_{\text {so }}$ & \multicolumn{5}{|c|}{4.05} \\
\hline \multicolumn{3}{|c|}{ Motor weight (kg) } & 11.60 & 10.92 & 13.92 & 11.82 & 13.82 \\
\hline \multicolumn{3}{|c|}{ EL $(\mathbf{k J})$} & 796.72 & 818.98 & 763.08 & 808.02 & 898.83 \\
\hline \multicolumn{3}{|c|}{ Efficiency (\%) } & 93.28 & 93.14 & 93.19 & 93.40 & 93.45 \\
\hline \multicolumn{3}{|c|}{$K_{\mathrm{e}}(\mathrm{V} / \mathrm{rad} / \mathrm{s})$} & 0.485 & 0.485 & 0.485 & 0.490 & 0.504 \\
\hline & $L_{\mathrm{ph}}(\mu \mathrm{I}$ & & 208.71 & 207.44 & 288.33 & 176.79 & 127.57 \\
\hline & $R_{\mathrm{ph}}(\mathrm{oh}$ & & 0.0438 & 0.0444 & 0.0471 & 0.0430 & 0.0406 \\
\hline & & $T_{\max }(\mathrm{Nm})$ & 133.34 & 133.23 & 133.20 & 134.63 & 138.59 \\
\hline Zone & & $\omega_{\mathrm{p}}(\mathrm{rpm})$ & 1491 & 1503 & 1547 & 1555 & 1620 \\
\hline Zone & & $P_{\max }(\mathrm{kW})$ & 26.10 & 26.11 & 26.17 & 26.57 & 27.21 \\
\hline Eone & & Rated torque @ 4094 rpm & 32.18 & 32.18 & 32.19 & 32.34 & 32.54 \\
\hline Zone I & & $\omega_{\max }(\mathrm{rpm})$ & 4320 & 4323 & 4324 & 4278 & 4156 \\
\hline
\end{tabular}

As expected, the 18/20 motor has a shorter end winding and a thinner back iron than the other two candidates, but it has a large radius because it has a large number of poles. Among the 18/20 candidate motors, Case 2 provides a motor with a minimum weight, but the worst rated efficiency; Case 3 has the least EL or the best driving-cycle efficiency, but the heaviest weight; and Case 
5 has the highest rated efficiency, but the highest EL. Case 4 and Case 5 were found to have a more than $15 \%$ additional EL than the motor designed by traditional approaches without considering the frequent operation points. Therefore, Case 1, in which both the motor weight and the EL during the driving cycles are minimized, is the best choice for further verification and refinement using FE analysis.

\section{Finite Element Analysis}

The above optimization results were obtained from the quasi-3D magnetic circuit model, which is usually relatively imprecise because of the assumption of linear properties and the simplified motor configuration. The exploded view of the proposed AFPM motor is illustrated in Figure 9a, where the motor housing on each side of the stator is responsible for dissipating heat loss via the water-cooling duct. It is necessary to apply FE analysis to verify the optimal design results. The magnetic flux density distributions in the rotor, stator, and air gap at the peak phase current of $200 \mathrm{~A}$ are illustrated in Figure $9 \mathrm{~b}, \mathrm{c}$. The maximum flux density of $1.8 \mathrm{~T}$ occurs at some locations on the stator teeth and the back iron as well as in the air gap along the outer radius near $95 \mathrm{~mm}$. Thus, the motor performances were analyzed in terms of the back EMF wave, the TN curve, the efficiency map, the EL over various driving cycles, and the heat dissipation properties.

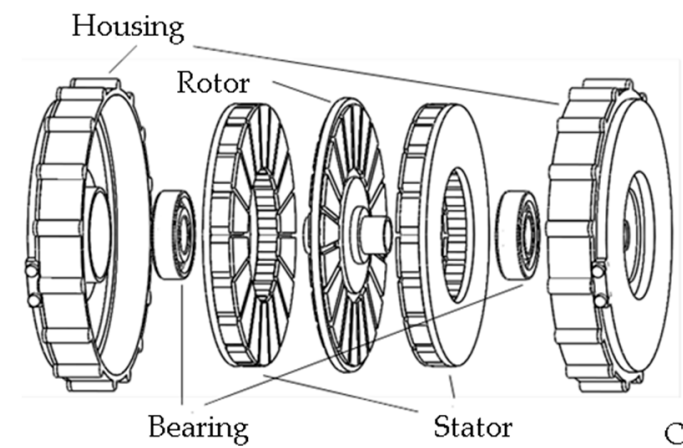

(a)
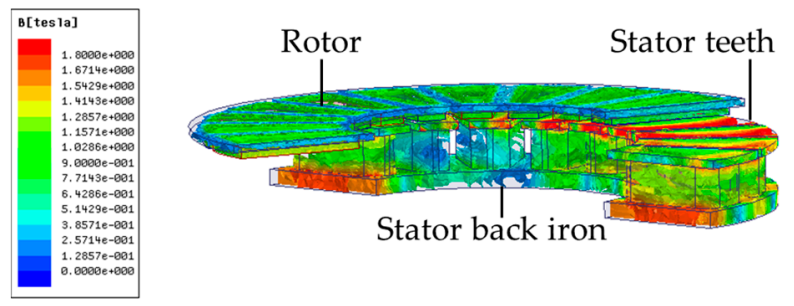

(b)

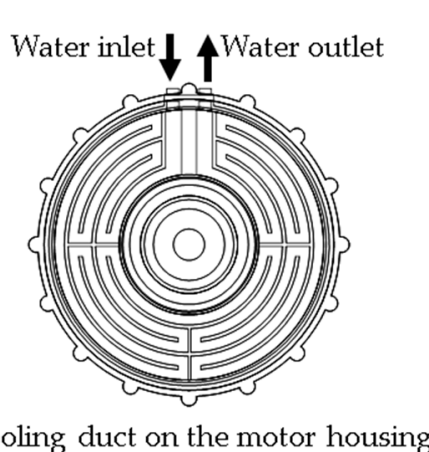

Cooling duct on the motor housing

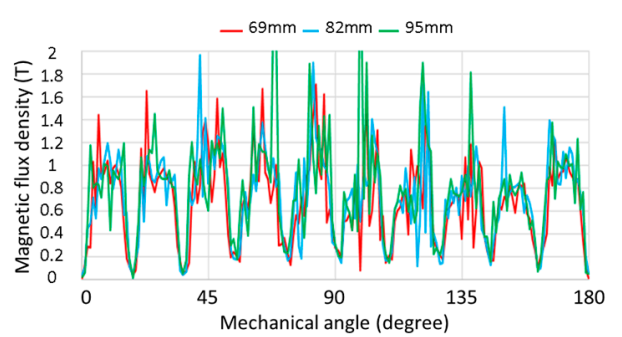

(c)

Figure 9. (a) Exploded view of the axial-flux permanent-magnet (AFPM) motor assembly and the S-shaped water-cooling duct on housing; magnetic flux density distribution in (b) the stator, the rotor; and (c) the air gap at various radii.

\subsection{Back Electromotive Force Constant Analysis}

The electromagnetic analysis tool, Maxwell 3D of ANSYS, was used to verify the performance of the motor that was designed using the quasi-3D magnetic circuit model. The back EMF wave of the motor was obtained by taking the derivative of the three-phase flux linkages. Without loading, the back EMF of the motor is close to a sinusoidal wave, which is composed of a fundamental harmonic of $91.99 \%$, a third harmonic of $6.72 \%$, a fifth harmonic of $0.52 \%$, and less than $1 \%$ of the rest higher order harmonics. The flux linkages of the $d$ and $q$ axes are transformed from the three-phase flux linkages. Without input current excitation, the $q$-axis flux linkage $\lambda_{\mathrm{q}}$ equals 0 , while the $d$-axis flux linkage $\lambda_{d}$ is $0.0473 \mathrm{~Wb}$, which is also the same as the magnet flux linkage $\lambda_{\mathrm{m}}$. Thus, the back EMF constant $K_{\mathrm{e}}$ is calculated as $0.473 \mathrm{~V} / \mathrm{rad} / \mathrm{s}$. This is approximately $2.47 \%$ different from the back EMF 
constant $K_{\mathrm{e}}$ found in Case 1 (Table 4), which was obtained using the magnetic circuit model, and it is within the lower and upper bounds required by the driving scenario shown in Table 2.

\subsection{Torque and Speed Curve and Efficiency Map}

Since the phase current $I_{\mathrm{ph}}$ is assumed to enter the $q$-axis, the torque versus phase current curve was obtained using the nonlinear FE tool, as shown in Figure 10a. This curve matches the dashed line with circles; each torque was calculated by substituting $K_{\mathrm{e}}=0.473 \mathrm{~V} / \mathrm{rad} / \mathrm{s}$ from the no load analysis into Equation (15). The larger error occurs at the high input current due to magnetic flux saturation.

The cross-coupling effect of the $d$-axis and $q$-axis inductances and the magnetic flux saturation were found to have little influence on the linearity between the $q$-axis flux linkage and the phase current, as shown in Figure 10b. The $d$-axis and $q$-axis inductances are $237.18 \mu \mathrm{H}$ and $244.37 \mu \mathrm{H}$, respectively. The maximum phase current $I_{\mathrm{ph} \text {-max }}=195.5 \mathrm{~A}$, which is a little lower than the maximum phase current value in the original motor that was designed using the quasi-3D magnetic circuit model, was found to satisfy the required maximum torque of $133.2 \mathrm{Nm}$. When that value was combined with the DC current limit $I_{\mathrm{DC}-\max }=81.8 \mathrm{~A}$, shown in Table 2, the resulting TN curve was obtained and compared with the TN curve required by the three driving scenarios and the TN curve obtained using the magnetic circuit model, as shown in Figure 10c.

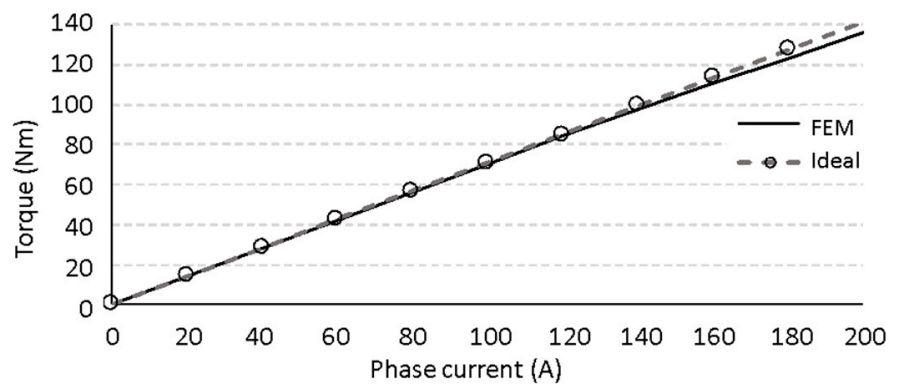

(a)

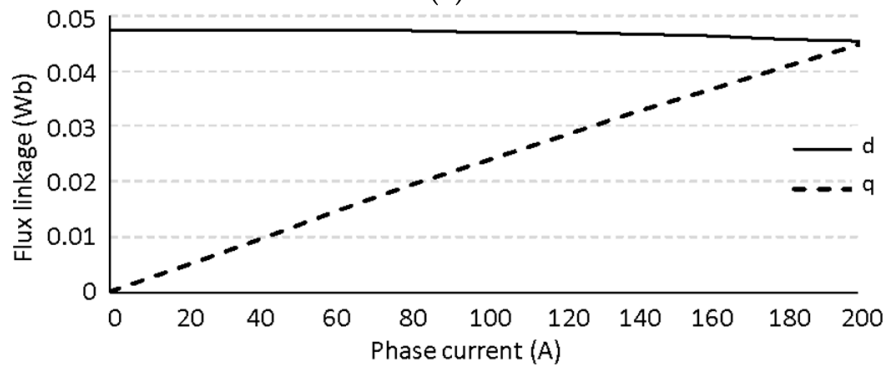

(b)

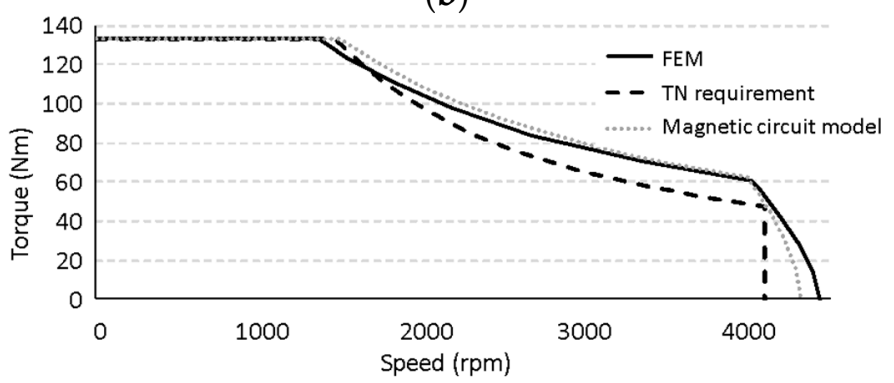

(c)

Figure 10. (a) Torque versus phase current curves from the ideal model of Equation (15) and the FE analysis; (b) $d$-axis flux and $q$-axis flux linkages versus the phase current; and (c) the resulting TN curve using the FE method as compared to the required TN curve and the TN curve obtained using the magnetic circuit model. 
It was found that the operation range of the proposed motor was wider than the TN curve that was obtained using the magnetic circuit model in zone III. As shown in Table 5, the maximum motor speed was increased by $2.5 \%$ because the final back EMF constant was smaller than the back EMF constant obtained using the magnetic circuit model. The difference in operation zone II is due to the fact that the phase inductance obtained using FE analysis is higher than the phase inductance obtained using the magnetic circuit model. Due to the coupling effect of phase inductance and resistance, the first corner speed from the FE analysis was found to be slightly lower than the required corner speed.

Table 5. Comparison of TN curve parameters.

\begin{tabular}{ccccccc}
\hline Model & $\boldsymbol{I}_{\mathbf{p h}-\mathbf{m a x}}(\mathrm{A})$ & $\boldsymbol{\omega}_{\mathbf{p}}(\mathbf{r p m})$ & $\boldsymbol{\omega}_{\mathbf{q}}(\mathbf{r p m})$ & $\omega_{\max }(\mathbf{r p m})$ & $\boldsymbol{K}_{\mathbf{e}}(\mathrm{V} / \mathrm{rad} / \mathbf{s})$ & $L_{\mathbf{p h}}(\mu \mathrm{H})$ \\
\hline Magnetic circuit & 183.3 & 1491 & 4023 & 4320 & 0.485 & 208.71 \\
FE & 195.5 & 1363 & 4010 & 4428 & 0.473 & 237.18 \\
error & $+6.7 \%$ & $-8.6 \%$ & $-0.3 \%$ & $+2.5 \%$ & $-2.5 \%$ & $+13.6 \%$ \\
\hline
\end{tabular}

Figure 11a shows the efficiency map obtained from the FE method. At the rated point, the motor efficiency $(93.40 \%)$ was found to be slightly higher than the motor efficiency $(93.28 \%)$ obtained from the magnetic circuit model, as seen in the optimal Case 1 shown in Table 4 . The efficiency difference between the FE and magnetic circuit models is shown in Figure 11b, and the difference is within the range of $-2.5 \%$ to $+3 \%$. This difference is caused by overestimating the iron loss in the low torque region and underestimating the copper loss in the high torque region.

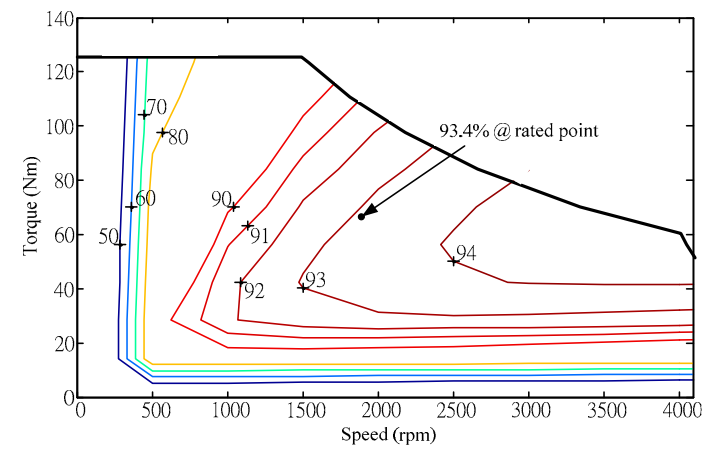

(a)

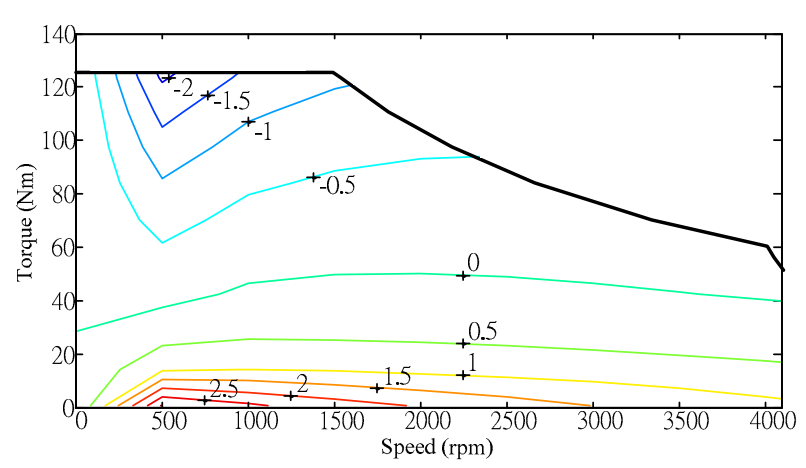

(b)

Figure 11. (a) Efficiency map from the FE method; and (b) efficiency map difference between the FE and magnetic circuit models.

\subsection{Energy Loss and Thermal Analysis}

Table 6 shows a comparison of the ELs from the proposed AFPM motor when four of the motors drive the four-wheel-drive passenger car with three driving cycles (FTP-75, NEDC, and JC08). In the FE analysis, the sinusoidal current was supplied to the motor without considering the higher-order current harmonics produced by the inverter switching. As seen in Table 6, the FE analysis resulted in higher copper loss, but lower iron loss, than the magnetic circuit model. The higher copper loss was caused by considering the temperature-dependent copper resistance. The lower iron loss was because the permeability of electrical steel was assumed to be much larger than the permeability of air, so the reluctance of steel was neglected in the magnetic circuit model. Thus, the magnetic flux density distribution in the air gap, the back EMF constant, and the torque are all larger than those obtained using FE analysis. Therefore, more current is required in the FE model to produce the same torque as found in the magnetic circuit model.

The rare-earth neodymium-iron-boron ( $\mathrm{NdFeB}$ ) magnet (magnetization grade $\mathrm{N} 35 \mathrm{SH}$ ) is used for the AFPM motor; its remanence is $1.14 \mathrm{~T}$ and the recoil permeability is 1.05 at $60^{\circ} \mathrm{C}$. The eddy-current loss in the magnet is relatively small, and it is about $3 \%$ of the total loss. In general, there is only about a $5 \%-7 \%$ difference in EL between the FE and magnetic circuit models. 
Table 6. Comparison of EL with different driving cycles. FEM: finite element model; MCM: magnetic circuit model.

\begin{tabular}{cccccc}
\hline \multicolumn{2}{c}{ EL (kJ/cycle) } & Copper Loss & Iron Loss & Magnet Loss & Total \\
\hline \multirow{2}{*}{ FTP-75 } & FEM & 106.98 & 255.52 & 11.19 & 373.69 \\
& MCM & 100.45 & 294.00 & - & 394.45 \\
\multirow{2}{*}{ NEDC } & FEM & 32.50 & 184.44 & 8.66 & 225.60 \\
\multirow{2}{*}{ JC08 } & MCM & 30.63 & 212.14 & - & 242.77 \\
& FEM & 42.15 & 103.91 & 4.10 & 150.16 \\
& MCM & 39.66 & 119.84 & - & 159.50 \\
\hline
\end{tabular}

During the operation of a motor, most EL is in the form of heat, which is dissipated through the water-cooling duct on each side of motor housing, as shown in Figure 9a. The S-shaped water duct on the motor housing is designed with a contact surface of $0.0535 \mathrm{~m}^{2}$, an average thermal resistance of $0.00411^{\circ} \mathrm{K} / \mathrm{W}$, an average convective heat transfer coefficient of $4544 \mathrm{~W} / \mathrm{m}^{2}{ }^{\circ} \mathrm{K}$; the pressure drop between the water inlet and outlet is $40.53 \mathrm{kPa}$. The computational fluid dynamics (CFD) tool in the Solidworks Flow Simulation is used to design the cooling system by considering cooling efficiency, flow resistance, and fabrication cost. Figure 12 shows the transient response of the maximum and average temperatures of various locations in the motor. Initially, the motor was set at an ambient temperature of $27^{\circ} \mathrm{C}$. A continuous power of $14 \mathrm{~kW}$ was assumed for the vehicle running on a $15 \%$ slope at $60 \mathrm{~km} / \mathrm{h}$, so that the motor produced a constant torque of $64.3 \mathrm{Nm}$ at a constant speed of $2091 \mathrm{rpm}$. The cooling water was fed into the motor housing at a flow rate of $12 \mathrm{~L} / \mathrm{min}$ to dissipate $971-\mathrm{W}$ power loss when the motor efficiency was about $93.5 \%$ at the operation point. The winding temperature increased rapidly from $27^{\circ} \mathrm{C}$ to $40{ }^{\circ} \mathrm{C}$ in the first three minutes, and the steady-state temperature was $43^{\circ} \mathrm{C}$. The magnet temperature increased relatively more slowly than the winding temperature before it reached a steady-state temperature of $45^{\circ} \mathrm{C}$ near 24 minutes. The maximum stator temperature near the stator teeth was close to the winding temperature, but the average temperature of the stator in steady-state was low after being cooled by water.

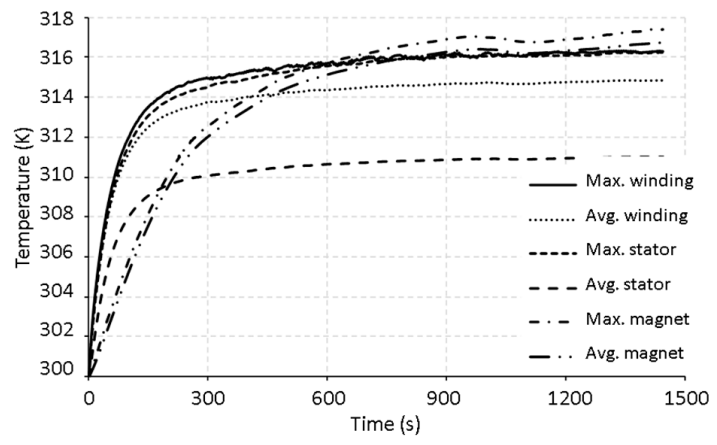

(a)

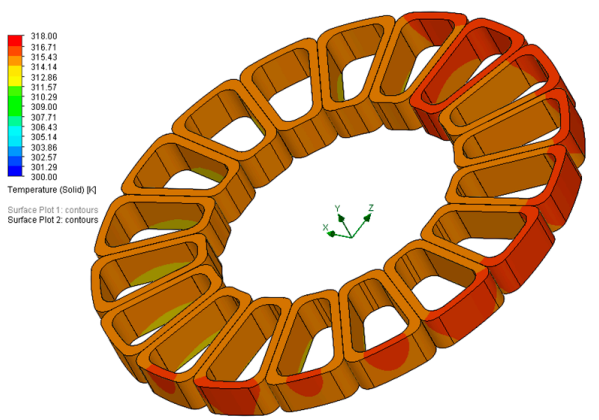

(c)

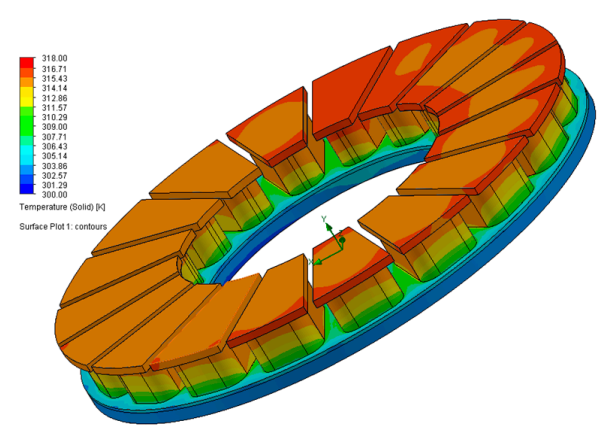

(b)

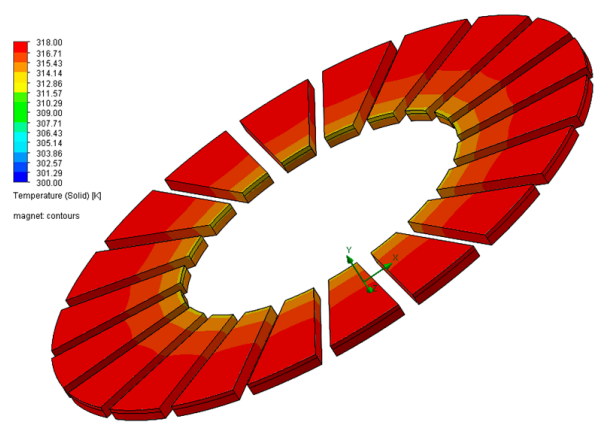

(d)

Figure 12. (a) Temperature response of the AFPM motor at continuous operation; temperature distributions in (b) the stator; (c) the winding; and (d) the magnet at the steady-state. 


\subsection{Re-Examination of Driving Scenarios}

This paper demonstrates a driving-scenario oriented design of an AFPM traction motor for EVs. The main purpose was to make the AFPM motor satisfy three driving scenarios without overdesign. Here, we re-examine the three driving scenarios: (1) the maximum slope that the vehicle can ride at a low speed is $35 \%$; (2) the vehicle can provide maximum acceleration under $40 \mathrm{~km} / \mathrm{h}$; and (3) the maximum cruise speed on a road with a $5 \%$ slope is $120 \mathrm{~km} / \mathrm{h}$. The first requirement determined the maximum motor torque of $133.2 \mathrm{Nm}$. The third requirement determined the motor's maximum speed $\omega_{\max }$, at which the torque $T_{\mathrm{c}}$ was much lower than the target torque of $47.58 \mathrm{Nm}$ at the corner speed $\omega_{\mathrm{q} 1}\left(=\omega_{\mathrm{c}}\right)$. Similarly, the continuous motor power, $P_{\mathrm{c}}=13.4 \mathrm{~kW}$, was set so that the vehicle was able to ride on a $5 \%$ slope at its maximum speed of $120 \mathrm{~km} / \mathrm{h}$. The continuous motor power was set about $66 \%$ of the maximum power of $20.4 \mathrm{~kW}$.

In the thermal analysis, the vehicle was assumed to drive on a $15 \%$ slope at $60 \mathrm{~km} / \mathrm{h}$ when a constant torque of $64.3 \mathrm{Nm}$ was required. This torque is less than the continuous torque setting at $66.6 \mathrm{Nm}$, which was half of the maximum torque of $133.2 \mathrm{Nm}$. This confirms that the setting of the continuous motor torque to half of the maximum torque is satisfactory for the driving scenarios. However, when more rigorous driving conditions are required, a higher continuous torque must be set. For a commercial product, the continuous torque and power are usually set at higher than half of their maximum values.

\section{Conclusions}

This paper proposed a systematic, driving-scenario oriented, multi-objective optimal design process of an AFPM motor for a four-wheel-drive EV. The driving scenario, the modulation method of the motor drive, and basic torque and voltage equations of the motor were used to provide basic information for building a range of target TN curves for three operation zones-constant torque, maximum DC current, and maximum voltage. Thus, the back EMF constant, phase inductance, and phase resistance were used to size and optimize the proposed motor using a quasi-3D magnetic circuit model. The systematic optimal design process for a preliminary motor design was fast and accurate, as verified through FE analysis. First, the resulting TN curve was found to match well with the target TN curve. The corresponding efficiency maps of the FE and magnetic circuit methods were also found to be similar, with a difference of less than $3 \%$. Second, the energy consumption of the proposed motor was $15 \%$ less than the energy consumption of the motor designed using a traditional method, which optimized the motor efficiency only at its rated operation point. Finally, the water-cooling duct was designed so that the motor dissipated EL during the operation. Moreover, the temperature response and steady-state temperature distributions were investigated, and it was proven that the proposed motor can be operated safely for a continuous driving mode.

Acknowledgments: The authors acknowledge the financial support of the National Science Council of Taiwan, Republic of China under Contract NSC 103-2221-E-002-001. They are also grateful for the partial support by the Mechanical and Systems Research Laboratories of Industrial Technology Research Institute in Taiwan.

Author Contributions: Yee Pien Yang conceived and designed the research and wrote the paper; Guan-Yu Shih conducted programming and analyzed the data.

Conflicts of Interest: The authors declare no conflict of interest.

\section{References}

1. Kahourzade, S.; Mahmoudi, A.; Rahim, N.A.; Ping, H.W. Sizing Equation and Finite Element Analysis Optimum Design of Axial-flux Permanent Magnet Motor for Electric Vehicle Direct Drive. In Proceedings of the IEEE International Power Engineering and Optimization Conference (PEDCO), Melaka, Malaysia, 6-7 June 2012.

2. Lindh, P.; Montonen, J.; Immonen, P.; Tapia, J.A.; Pyrhonen, J. Design of a traction motor with tooth-coil windings and embedded magnets. IEEE Trans. Ind. Electron. 2014, 61, 4306-4314. [CrossRef] 
3. Zhu, Z.Q.; Howe, D. Electrical machines and drives for electric, hybrid, and fuel cell vehicles. Proc. IEEE 2007, 95, 746-765. [CrossRef]

4. Qi, G.; Chen, J.T.; Zhu, Z.Q.; Howe, D.; Zhou, L.B.; Gu, C.L. Influence of skew and cross-coupling on flux-weakening performance of permanent-magnet brushless AC machines. IEEE Trans. Magn. 2009, 45, 2110-2117. [CrossRef]

5. Zhu, Z.Q.; Azar, Z. Torque speed characteristics of switched flux permanent magnet machines. COMPEL Int. J. Comput. Math. Electr. Electron. Eng. 2012, 31, 22-39.

6. Mignot, R.B.; Dubas, F.; Espanet, C.; Chamagne, D. Design of Axial Flux PM Motor for Electric Vehicle via a Magnetic Equivalent Circuit. In Proceedings of the 2012 First International Conference on Renewable Energies and Vehicular Technology (REVET), Hammamet, Tunisia, 26-28 March 2012; pp. 212-217.

7. Krebs, G.; De Cecco, E.; Marchand, C. Design Approach of an Axial Flux Motor for Electrical Powertrain Vehicle. In Proceedings of the International Conference on Electrical Machines (ICEM), Marseille, France, 2-5 September 2012; pp. 2812-2817.

8. Mohan, N.; Undeland, T.M.; Robbins, W.P. Power Electronics: Converters, Applications, and Design, 3rd ed.; John Wiley \& Sons: New York, NY, USA, 2002.

9. Parviainen, A.; Niemela, M.; Pyrhonen, J. Modeling of axial flux permanent-magnet machines. IEEE Trans. Ind. Appl. 2004, 40, 1333-1340. [CrossRef]

10. Chung, M.J.; Gweon, D.G. Modeling of the armature slotting effect in the magnetic field distribution of a linear permanent magnet motor. Electr. Eng. 2002, 84, 101-108. [CrossRef]

11. Hanselman, D. Brushless Permanent Magnet Motor Design, 2nd ed.; The Writer' Collective: Cranston, RI, USA, 2003.

12. Azzouzi, J.; Barakat, G.; Dakyo, B. Quasi-3D analytical modeling of the magnetic field of an axial flux permanent-magnet synchronous machine. IEEE Trans. Energy Convers. 2005, 20, 746-752. [CrossRef]

13. Ishak, D.; Zhu, Z.Q.; Howe, D. Permanent magnet brushless machines with unequal tooth widths and similar slot and pole numbers. IEEE Trans. Ind. Appl. 2005, 41, 584-590. [CrossRef]

14. Yang, Y.P.; Ding, F.X. Driving-scenario oriented design of an axial-flux permanent-magnet synchronous motor for a pedal electric cycle. IET Electr. Power Appl. 2015, 9, 420-428. [CrossRef]

15. Yang, Y.P.; Luh, Y.P.; Cheung, C.H. Design and control of axial-flux brushless DC wheel motors for electric vehicles-Part I: Multiobjective optimal design and analysis. IEEE Trans. Magn. 2004, 40, 1873-1882. [CrossRef]

(C) 2016 by the authors; licensee MDPI, Basel, Switzerland. This article is an open access article distributed under the terms and conditions of the Creative Commons Attribution (CC-BY) license (http:/ / creativecommons.org/licenses/by/4.0/). 